\title{
Investigating the impact of non-linear geometrical effects on wind turbine blades Part 1: Current status of design and test methods and future challenges in design optimisation
}

\author{
Find M. Jensen ${ }^{1}$, Amit S. Puri ${ }^{2}$, John P. Dear ${ }^{2}$, Kim Branner ${ }^{1}$, Andrew Morris ${ }^{3}$, \\ ${ }^{1}$ Wind Energy Division, Risoe National Laboratory for sustainable energy, \\ Technical University of Denmark, P.O. Box 49, DK-4000 Roskilde, Denmark \\ ${ }^{2}$ Department of Mechanical Engineering, Imperial College, London, South Kensington Campus, \\ London SW7 2AZ, UK \\ ${ }^{3}$ E.ON Engineering Ltd, Technology Centre, Ratcliffe on Soar, Nottingham, NG11 0EE, UK \\ • Corresponding author. Tel.: +45 4677 5054; fax: +45 4677 5960; e-mail address: fimj@risoe.dtu.dk
}

\begin{abstract}
This paper is the first part of a three paper series and it deals with full-scale tests of a load carrying box girder. The two other papers present more details on smaller sub component level as well as cap specimens (paper 2) and shear web (paper 3). This paper also links to the two other papers and brings the main results from them into the relevance for a wind turbine blade designer.
\end{abstract}

The investigated failure modes in all three papers relate to the Brazier effect, which is expected to be the key dominating failure mechanism in future wind turbine blade designs. Brazier effect may also have a significant impact on present wind turbine blades. In this paper a $34 \mathrm{~m}$ long load carrying box girder has been tested in static flapwise bending and it has been demonstrated that, for this design, Brazier effect is a critical phenomenon of great relevance for the ultimate failure strength. 
The box girder has been evaluated with and without a cap (wire) reinforcement. The cap reinforcement is one out of seven inventions Risø DTU published in 2008, and which all are intended to result in lighter and more reliable blade design.

Keywords: Brazier effect, full-scale testing, wind turbine blades, non-linear finite element, ultimate failure, interlaminar failure, skin debonding. 


\section{Introduction}

\section{Motivation}

The size of wind turbine blades is expected to increase considerably in the future as initiatives to increase the contribution to energy production from renewable energy sources accelerate. Since future blades are expected to be lighter a consequential increase in the longitudinal curvature will result, which in turn will lead to a quadratic increase in the crushing pressure resulting from flapwise curvature, see ref. [1]. In order to achieve this weight reduction, a better understanding of the ultimate failure load of composite turbine blades is required. The detailed structural behaviour must be investigated beyond the elastic range, including identification of failure modes leading to ultimate collapse. Such failure modes typically include combinations of large, geometrically nonlinear deformations such as buckling, local instabilities such as wrinkling and material non-linear effects such as fibre failure, matrix cracking, skin debonding and interlaminar failure. Furthermore, effects from manufacturing imperfections need to be considered. It is anticipated that the construction of offshore wind farms will increase in the future, with larger wind turbines needed to satisfy project economics. Hence, ensuring the design integrity and through life durability of wind turbines located in such arduous environments is crucial if the perceived commercial and environmental benefits are to be realised.

\section{State of the art}

So far wind turbine blades have typically been optimized through a combination of testing and simplified analytical and numerical methods. However, numerical simulation tools are gaining wider acceptance as they become more effective in their predictive capability, thus offering a route to lower development costs and increase reliability. 
In Figure 1 a pyramid representing a multi-scale approach to testing is shown. This pyramid is a collection of tests which have been performed at Risø DTU over the last 4-5 years. However, only full-scale tests (level 1) and the small coupon tests (level 5, right), such as materials data tests, are required by the certifying agencies when preparing the documentation forming the basis for type certification, see ref.[2],[3],[4].

Risø DTU's aim is to systemize subcomponent testing (levels 2-5) so that such testing can be used in a design and certification process. This approach has also been used in recent years by wind turbine manufacturers or certification bodies, see ref. [3],[5],[6],[7]. The approach is expected to be adopted in the certification process in the future, see ref. [2],[4],[9],[10]. In the latest version of "DNV-Risø Guideline for design of wind turbines", published in 2008, a description of this approach, called 'Building block approach', can be found, see ref. [4]. In ref. [11] stochastic models for strength of wind turbine blade using experimental results on different levels are presented. Load application in level 1 testing is traditionally very simplistic and, only separate flap and edge-wise load cases are required by the certification bodies, see ref.[3],[12]. Examples of more sophisticated load applications may be found in [13],[14].

An important geometrically non-linear effect is the so-called Brazier effect originally published by Brazier in 1926 [1]. Since 1911 with a publication by von-Karman [15], it has been recognised that thin-walled, hollow structures, under bending, suffer a flattening of the cross-section. The effect described by Brazier, is resulting from curvature, when bending a beam or a slender structure. Because of the curvature the longitudinal compressive and tensile stresses result in transverse stresses towards the neutral plane of the beam. This causes flattening of a hollow cylinder or suck-in deformation of a hollow box.

This effect has recently been addressed in failure analysis of wind turbine blades, see ref. $[16],[17],[18],[19]$. The transverse stresses causing the flattening are sometimes referred to 
as the crushing pressure, since the same effect would occur if an external pressure was applied (see Figure 2).

Recently a series of full-scale tests have been carried out at Risø DTU in Denmark so as to efficiently optimize a $34 \mathrm{~m}$ blade design from SSP-Technology $\mathrm{A} / \mathrm{S}$ in a combined experimental and theoretical approach. First, a full scale $34 \mathrm{~m}$ blade was tested to failure in flap-wise loading, see ref. [16],[20]. Ovalisation of the load carrying box girder was measured in the full-scale test and simulated in non-linear FE-calculations, see ref. [17],[21]. The nonlinear Brazier effect was characterized by a crushing pressure which caused the ovalisation. A global non-linear FE-model of the entire blade was prepared and compared with the experimental results (see Figure 3). Strain gauge measurements helped identify the location of failure initiation which leads to catastrophic failure, see Figure $3 \mathrm{~b}$.

Figure 3a shows a frozen frame picture from a video recording failure of a box girder in fullscale test. It shows initial face debonding of the outer skin on the shear web's sandwich section, leading to ultimate collapse of the box girder.

Comparisons between measurements and FE-simulations showed that buckling of the load carrying cap (flange) was the initial failure mechanism followed by skin debonding in the shear web which then led to collapse as shown in the sketch in Figure 3b. The pre-buckling of the cap could be caused by interlaminar failure. To judge whether interlaminar failure is critical more research is needed and this is done in this paper.

\section{$\underline{\text { Aim and current work }}$}

The principal aim of this paper and the two related papers ref. [22],[23] is to investigate failures in cap and shear webs. Both, full-scale test of a $34 \mathrm{~m}$ long load carrying box girder and sub component tests have been performed and the results from the analyses are shown in these three papers. Three series of subcomponent tests indicated in Figure 4 have been performed and analyzed. The failure related to the cap is covered in the part 2 paper and 
failure related to the shear web is covered in the part 3 paper. Paper 3 presents both experimental testing of a box section and column buckling test of sandwich specimens. The sandwich specimens are in compression (column test), representing the crushing forces in the shear web sandwich panel. Some of the sandwich specimens are manufactured with a defect, representing what can be found in a real wind turbine blade. This paper discusses the relevance of these sub component tests.

The specific aim of this paper is to relate these sub component tests so that they have relevance for wind turbine blade designers. The loads in all three subcomponent tests represent the crushing pressure from the Brazier effect which contributes to the non-linear distortion (ovalisation).

Testing of cap specimens have been performed both with and without cap reinforcement. The experimental results and experimental configuration of the cap specimen tests and the FEstudies are presented in paper 2. In this paper only key figures from the section tests are included and compared with deflection measured in a full-scale test of a similar blade. Two other full-scale tests are also presented in this paper: one with and one without the cap (wire) reinforcement shown in Figure 5. This would have a similar benefit as that employed by a roof truss. 


\section{Potential for weight reduction in modern wind turbine blades}

Large differences can be found in the safety margins against various types of failure modes, which indicate that current wind turbine blade designs need to be optimized to a higher degree with regards to structural strength as presented in this paper. Failure can originate from the material, imperfections in the structure and from buckling. The safety margin against different failure modes in current designs is illustrated in Figure 6. This is done in order to illustrate the potential for fuller use of the material's strength properties e.g. for in plane loading in present wind turbine designs, see ref. [24].

Figure 6a illustrates that the material strength (in plane loading) has a very large safety margin in modern wind turbine blades. This observation is based on experimental work $[25],[26],[27],[28]$ where panels from three blade manufacturers have been tested in compression The panels which have been tested represent the load carrying laminates which are positioned in the outer shelves in the area close to the shear webs often called caps. The loading conditions (in-plane compression) and the materials, layups and the production methods were similar to the actual blade. The major difference from these test panels and real caps are that the test panels are flat, while a real cap panel have a small transverse curvature. Of course this can result in some discrepancy, but it is not expected to have a major influence on the results. Strains measured in the panel tests from ref. [28], were in the range of 20$30000 \mu \mathrm{S}$, which is a factor of 4-6 times higher than strain measured in full-scale tests (3$5000 \mu \mathrm{S})$, see ref. [20],[29],[30].

For panels with a large embedded defect the strain levels were in the range of 10-20000 $\mu \mathrm{S}$, which is a factor $2-5$ higher than obtained in full-scale tests.

Figure 6 also illustrates that the future optimized safety chain concept can carry double the load of the chain shown representing current wind turbine blades. This illustrates how we 
believe that the safety margin (or reliability) of future wind turbine blades can be increased. Of course other effects such as ageing effects, temperature variability etc. should be included in the final approval. This work is only accounting for the defects which are in this particularly blades and do not take aging and temperature effects into account. To achieve this, the blade should be strengthened to account for both the "Material strength-out of plane loads" and "Structural strength" links. In this paper (and papers $2+3$ ) only the delamination failure modes are discussed. To study the optimization of the "Structural strength" link, Find M. Jensen's $\mathrm{PhD}$ thesis ref. [16] or the related patents should be studied, see ref. [31],[32],[33],[34],[35],[36],[37]. Here only one example is shown in order to illustrate what is meant with "Structural strength". The example is a shear distortion failure type which does not often get much attention in current blade designs. In Figure 7a, the shear distortion failure mode is shown, which can easily be prevented by either a cross (Figure 7b) or tilted shear webs, see Figure 7c.

By solving this problem and the other "Structural strength" problems shown in ref. [16] as well as the delamination problems, presented in the following, lighter and more reliable blades are expected for the future. The specific safety margin which are obtained by these novel structural solutions suggested e.g. in ref. [16] are difficult to estimate, but numerical studies and full-scale tests have shown that when the structural members e.g. a cross is inserted in the blade then the blade fail in another mode at a higher load. Furthermore, the tip clearance problem has to be solved since the reduction of material in the load carrying laminates increase the tip deflection linearly. Today there exist ways to solve that problem e.g. cone, tilt or prebend the blade, but it may influence in a small reduction in the aerodynamic efficiency which has to be taken into account. 


\section{Delamination failures}

Two delamination types of failure, interlaminar shear failure and sandwich skin debonding are analyzed in this paper. Other delamination types of failure such as buckling driven delamination, adhesive joint debonding etc. are also relevant for the ultimate strength of wind turbine blades, but are not treated here. In this paper only a short description of the failure modes and the sub component tests are analyzed. In paper 2 interlaminar shear failure in the load carrying cap is analyzed and in paper 3 skin debonding in the sandwich shear webs is analyzed.

\subsection{Interlaminar shear failure in the load carrying cap caused by Brazier loads}

Interlaminar shear failure is a mechanism that can occur between the layers in a composite panel and is observed in the failure of the load-carrying cap laminate, see Figure 8a. The failure is caused by interlaminar shear stresses. The interlaminar shear failure can be developed by the crushing pressure causing biaxial stress distributions, interlaminar and peeling stresses due to the curved structure being flattened out, see Figure 8a. Brazier effect cause the out-of-plane deformation of the cap.

A typical lay-up is not particularly well suited to reduce cap deflections, since the fibres are mainly placed in the longitudinal direction of the blade. The lack of fibres in the transverse direction causes the cap to be relatively flexible in the lateral direction. When the cap deflects there is a risk of transverse failure in the unidirectional laminates interlaminar failures, potentially stemming from matrix cracks, see ref. [16]. Interlaminar failure could be critical since there are both mode I (opening) and mode II (shear) interlaminar stresses. Layered composite materials do not have large resistance against peeling (mode I) and interlaminar stresses (mode II), which may lead to failure. Figure $\mathbf{8 b}$ shows large delaminations found in the load carrying cap after collapse. Furthermore, it is common that manufacturing imperfections inside the laminate further reduces the limit for the peeling stresses. To further investigate the interlaminar failure observed after full-scale tests, cap specimens from a "old" 
(blade has been used in a static full-scale test) SSP $34 \mathrm{~m}$ blade were cut out and tested in two different bending tests. The description of the tests and detailed results are presented in paper 2 , here only the main results are included to show the relevance to wind turbine blades. The two bending tests (3-point and distributed-loading) showed that matrix cracking initiated early on in the loading, when the strain in the UD layers exceeded $4000 \mu$ strain, represented by 8 $10 \mathrm{~mm}$ cross-head displacement in Figure 9. Following on from this delamination growth initiated at central deflections of approximately $8 \mathrm{~mm}$ and became visible around $10 \mathrm{~mm}$, resulting in a reduced stiffness, see Figure 9c. Note that the level of load distribution increased significantly after $14 \mathrm{~mm}$ cross-head displacement, leading to a rise in the slope. Use of Digital Image Correlation (DIC) techniques provided strain results that first indicated the matrix crack, and then allowed identification of the elevated stresses ahead of the matrix crack tips which contributed to delamination growth between the biaxial/UD interface. The DIC-system is an optical system which can measure three dimensional surface deformations using two cameras.

From a full-scale test analyzed in ref. [16],[17],[29] the cap deflections were in the range of 1-6mm, so lateral bending stiffness of the caps may be too small to avoid matrix cracking see

\section{Figure 10.}

\subsection{Skin debonding from the sandwich core in the shear web}

Web failures have been observed as the main reason for collapse in the first two full-scale tests, see Figure 3 from ref. [16],[21]. Figure 3 presents a frozen frame picture of the critical, failure mode of the box girder full-scale test. In the white circle in Figure 3, initial face debonding of the outer skin on the shear web's sandwich section is seen as a light green colour, leading to ultimate collapse of the box girder. This failure mode is caused by a complex load and strain distribution described in ref.[21]. Here and in paper 3 only one load component (Brazier load) is taken into consideration and therefore much more experimental 
work should be done before a full understanding of the influence from all load components can be obtained. The Brazier load component analyzed here and in paper 3 is expected to be the dominating effect in future since, more flexible blade design with larger longitudinal curvature, so maybe for a future design process the sub component tests addressed here give a good estimate of the shear web strength.

\section{Description of sub component tests performed}

\subsection{Box section test and FE-model}

To better understand the influence of a crushing pressure on the failure mode of a box girder, the structure was separated, sectioned, and tested under flexure loads in isolation. Tests were performed using a constant displacement ramp of $0.14 \mathrm{~mm} / \mathrm{s}$ and a three point loading arrangement. The DIC technique was used for strain mapping on the sandwich webs to fully appreciate both the differences between this section testing and full blade testing, as well as the evolution of strain with applied load. The out of plane displacement result is shown in Figure 11a. The high levels of shear led to shear fracture of the core, which resulted in collapse of the structure, as shown in Figure 11b. A thorough description of the experiment and the results is given in paper 3 [23]. In relation to the delamination failure described in section 3.1, the full blade tests have shown that core shear fracture is more likely to occur before cap delamination, but it is highly geometry dependent, and cap delamination is still a relevant failure mode.

In ref. [39] three specimens cut from the load carrying box girder of a $25 \mathrm{~m}$ wind turbine blade were tested to failure under a type of 3-point bending. Finite element analyses were performed to investigate different non-linear approaches and compare these with the experimental results. The FE model is plane and constructed with 2D-solid Quad4 elements. The caps are constructed with mainly UD-laminates combined with some Biax-laminates. 
The UD-laminates have the fibres in the longitudinal direction of the blade (perpendicular to model plane). The UD and Biax parts generally have 3 elements in the thickness direction, resulting in up to 37 elements in total for the flange in the thickness direction. The webs are sandwich structures with Biax skins and a foam core. In the thickness direction 3 elements are used for the skins and 4 elements for the core. The model has a total of approximately 73000 elements. Geometrical non-linearities and an elastic-ideal plastic material model for the foam were taken into account in the FE analyses. The calculated deformation of the webs was found to be close to that observed in the experiments immediately before failure. Very high shear strains were predicted for the lower and upper parts of the webs leading to increasing bending curvature at the middle of the webs (observed as localization in the experiments). The probable reason for ultimate failure is therefore shear fracture of the core in the box girder webs, leading to delamination and ultimate failure. Today no fracture mechanics approach is included in the FE-model, so initiations can be detected from the FE-model and therefore no confirmation other than high stress-levels. Future FE-models are expected to include a fracture mechanics approach such as cohesive interface elements or VCCTelements, see ref. [38]

Similar tests have been performed before, see ref. [21],[39]. The major difference presented here made use of more sophisticated measuring equipment such as DIC, which gave a full surface deformation and strain picture of the deformed section and reveals how the web ovalises asymmetrically, Figure 11a.

\subsection{Column tests of sandwich panels representing the shear webs}

As a development of the box section tests, column buckling experiments were performed to understand the variables attributable to the failure of the sandwich webs. The experiment was designed around the standard test method ASTM C364 [40],[41], where the gauge length was increased to promote buckling. Laboratory manufactured specimens had a $20 \mathrm{~mm}$ core and 
two skins with a four biaxial layers $\pm 45^{\circ}$. The grades of the skin were varied to achieve three different skin/core thickness ratios.

This ratio was important in determining the initial failure mode, where the thinner skinned material was more prone to skin fracture, whilst the thicker skinned material incurred core shear collapse. Both of these failures led to global buckling. As the skin thickness increased there was a proportional increase in the strength and ultimate load. The biggest difference observed was in observations of specimens manufactured with incorporated interlaminar delaminations. With these inclusions, the specimen failure occurred at a reduced load, which was seemingly proportional to the skin to core thickness ratio, although sufficient data points were not collected to corroborate this. Additionally, there was a shift in the failure mode, which most incorporated delamination growth, especially in the thinner skinned material. Interfacial delaminations were also incorporated into specimens, but a strength reduction was not observed with this defect type.

To further understand the buckling behaviour the experiments have been modelled with FE using realistic loading behaviour including shear force longitudinal bending. The results are presented in greater detail in paper 3.

\subsection{Cap specimen tests}

To better understand the failure process and loss of load bearing capacity of the cap, tests were performed on a specimen box girder cross-section. Tests were performed by flexural loading the specimens to directly simulate the crushing pressure, as shown in Figure 4. Simplifications of the test were made by using both three-point and distributed (pressure) loading. Figure $9 \mathrm{c}$ shows that the distributed loading is very similar to the three point loading applied. This is because the distributed loading rig starts off with loading across a section length of approximately $100 \mathrm{~mm}$, which progressively increases to $400 \mathrm{~mm}$ as the curvature changes under applied load, at which point the test is stopped to ensure the rig is not 
damaged. Thus in the early stages the stresses were highest at the centre of the specimen for both tests. This remained the case for the three point specimen, which failed due to the tensile fracture of the bottom most biaxial layer following on from high levels of matrix cracking in the bottom most UD layers, Figure 9a, which was the same failure mode as described in section 3.1. Yet for the distributed loading specimen, the stress was spread across a larger region, leading to $150 \%$ greater dispersion of the matrix cracking across the bottom most UD layers. As these matrix cracks induce delamination growth, greater levels of delamination growth were seen across the specimen.

Building upon this, the specimens with transverse cap reinforcement were tested with the distributed loading rig. The reinforcement concept is highlighted in Figure 5c, and was achieved by moulding 3 UD layers of glass fibre in the transverse direction across the curvature of the cap. The resulting structure was able to hold more than double the load at a given displacement than its unreinforced counterpart. Furthermore the reinforcement reduced the degree of matrix cracking and thus the amount of delamination growth was also reduced. However, the failure was more brittle and the higher forces resulted in peeling of the reinforcement (as the test was displacement controlled).

These experiments were modelled using 2D plane stress elements for the glass fibre, and 2D cohesive elements for the interlaminar layers. Using Hashin's theory to show transverse (perpendicular to the length of the blade) tensile damage it was seen that the crushing pressure led to high levels of transverse matrix cracking, a result that verifies the DIC evaluated results from the experimental phase. The results are presented in greater detail in paper 2.

\section{Full-scale test of a box girder with and without cap reinforcement}

Based on experience from a full-scale test a new $34 \mathrm{~m}$ box girder from SSP-Technology AS was manufactured and tested. Holes were drilled in the box corners so wire reinforcement could be inserted between the corners, see Figure 5. 
The wire reinforcement prevents the load carrying cap laminate from deflecting inwards, so buckling strength and interlaminar failure are less critical.

The wires are used only to validate the effect of coupling the corners. Obviously, a different solution should be found if manufacturers want to implement this invention in their blades. This, was used only for demonstration of the invention's structural effect. In Figure 5c one manufacturing solution is shown. More embodiments can be found in ref. [31].

The current paper shows the main results from these two full-scale tests with and without wires. The comparison demonstrates the positive effect of this cap(wire) reinforcement.

\subsection{Description of the invention: 'Cap reinforcement'}

The invention presented here is a reinforcement of the cap, which limits the ability of a curved (aerodynamic shape) cap from flattening out; see Figure 12 from ref. [31].

The restriction of the out of plane deformation of the cap is caused by restraining the corners from sideward deformations, thus increasing the flexural stiffness of the cap. The reinforcement is expected to be thin in comparison to the cap thickness, since it should carry only tension. Increased flexural stiffness (in the out-of-plane direction) of the cap decreases the possibility of buckling and interlaminar failure when comparing with a design without reinforcement.

Also wires or pins can be used, as showed in Figure 13c. A special wire solution, shown in [16], was used in the full-scale test, since it was the simplest solution to implement in an existing box girder. This solution could probably not be used in practice since the steel wires will attract the lightning, but in a 'proof of concept' test it is satisfactory.

The cap reinforcement can be made of any material, such as wires, fibres, dry fibre mats etc. as it needs only to carry tension. In Figure 13a, a dry fibre mat is presented and a pultruded 
profile is shown in Figure 13b. Pultruded profiles, which have not yet been used as load carrying parts in wind turbine blade design, may be an interesting alternative.

In Figure 13, three structural solutions are shown. More solutions can be found in patent application ref. [31].

\section{$\underline{\text { Proof of Concept of the cap reinforcement invention }}$}

A proof of concept test was performed for the cap reinforcement. The work includes numerical and experimental work, but here only the experimental results are presented. Two full-scale tests were performed in order to validate the ability of the cap reinforcement to reduce out of plane bending of the load carrying laminate (cap), see Figure 14.

Based on a FE-study two areas were found critical to buckling and cap reinforcement (wires) was placed in these two regions. One critical region was the $5 \mathrm{~m}$ section, where three wires were placed to prevent buckling, see Figure 15.

Another critical region was the $10-12 \mathrm{~m}$ section which is shown in Figure 16. The big difference in the transverse curvatures of these two regions (5m and $10-12 \mathrm{~m})$ can be observed, see Figure 15b and Figure 16b.

FE-studies which were performed before the full-scale test showed that the reinforcement should have an effect also in regions with small transverse curvatures. The same results were observed in the full-scale test using the DIC system, see Figure 17. The graphs in Figure 17 present a comparison between the two full-scale tests (with and without wires), where the effect of the wires is demonstrated. In figure 17, the deformed centrelines from the two tests of the cap along the blade are plotted. The blue line shows results from test with wires and the red from test without wires. 
The out of plane deformation of the cap is reduced by $10-30 \%$ due to the wires. As expected it is mainly the buckling waves which bend inwards that have been reduced. For instance, sections $10 \mathrm{~m}$ and $11.5 \mathrm{~m}$ have reduced their deformations by around $30 \%$, while sections $10.8 \mathrm{~m}$ and $11.8 \mathrm{~m}$ only have reductions around $10 \%$, see Figure 17.

Not only have the out of plane deformations decreased due to the cap reinforcement, but the measured strain has also been reduced. In Figure 18, the measured transverse strains are plotted, for section $10.8 \mathrm{~m}$ and $11.5 \mathrm{~m}$.

In Figure 18a, a slight slope change after $70 \%$ loading are observed also for the case with "wires". The non-linearity is caused by buckling of the cap, which can also be seen in the measured out of plane measurement from Figure 17. The test with cap reinforcements did not show any tendency to buckling even though the box girder was loaded up to $95 \%$ load. The load scale refers to an ultimate failure of a full-scale test including the outer foil of the blade. If these observations can be generalized, it can be concluded that the buckling capacity has been increased by at least $35 \%$ and maybe more if the loading of the box girder had been increased further. 


\section{Conclusion}

This paper is the first in a series of three papers which deals with full-scale tests of a load carrying box girder from a $34 \mathrm{~m}$ wind turbine blade. The two other papers present more details on testing of smaller sub components, namely cap specimens (paper 2) and shear web specimens (paper 3). This paper links with the two other papers to bring the main results from them into relevance for a wind turbine blade designer. Specifically the key findings of the cap results are that the 3 point loading of the cap geometry reveals similar, although slightly inferior bending results when compared to distributed loading; and that the glass fibre 'wire' reinforcement can more than double the load bearing capacity of the cap sustained Brazier's loading. The key findings of paper 3 is that the asymmetric ovalisation of the box section can lead to shear disbond of the sandwich webs, and that delaminations rather than disbonds present in the shear webs will lead to significantly premature buckling.

The failure modes investigated in all three papers relate to the Brazier effect, which is expected to be one of the dominating failure mechanisms in future wind turbine blades.

Two full-scale tests of a $34 \mathrm{~m}$ box girder were performed, one with and one without wire reinforcement. The wire reinforcement prevented the load carrying cap laminate from deflecting inwards, so buckling strength and interlaminar failure are less critical as expected. The experimental results showed that the cap reinforcement reduces both the local deformation of the cap and the strains by $10-30 \%$. Furthermore, the buckling capacity has been increased by $35 \%$, and there is potential to improve this further. These design optimisations have regard for the demanding operational conditions to which blades are subjected.

Regardless of the wire reinforcement, the local deformations are expected to cause an interlaminar failure mode between the layers in the cap laminate, potentially arising from matrix crack growth transverse to fibre direction. This can be concluded after having compared deformations measured during the full-scale test and the cap specimen tests. It may 
in some cases have been concluded that the blade failed due to buckling instead of interlaminar failure. This is an obvious conclusion if deformation strains are studied alone, but interlaminar failure should also be considered as one of the critical failure mode. The authors believe that if the interlaminar failure can be prevented then the buckling capacity also increases significantly. The cap reinforcement tested here does decrease the possibility of the interlaminar failure, but at the same time it also increases the buckling capacity, so it is difficult to give an accurate estimate how much each failure mechanism has changed. The interlaminar failure is not only a problem at compressed cap (suction side) but also on the cap in tension (pressure side). Today it may not be so pronounced since the two caps are almost symmetric but future and optimized blades may have significantly less layers in the cap in tension, due to the fact that composite materials can carry much more in plane load than those currently designed. This old fact, from other industries, has been published for the first time for composite for wind turbine bladders in ref. [28], so now the focus is to find the "real" weak points in the structure. One of them could be debonding of the skin from the sandwich core in the shear webs. This failure has been studied in two different sub component tests analyzed in paper 3 . 


\section{Future work}

Creep failure of wind turbine blades is known to be a challenge in the wind turbine industry. When performing the required static tests, as part of the certification process, the blade is usually offloaded quickly after a short hold at the required test load. This is particular true for blades with parts in wood, but also polymer foams and fibre reinforced plastics are viscoelastic materials and the strain will increase over time when subjected to a constant loading. This can lead to creep failure.

During sub component tests, the materials viscoelasticity, have also been observed. It is not fully understood how the viscoelastic material properties and creep influence the strength and damage propagation in wind turbine blades and their sub components. The siting of wind turbines will expose them to a range of climatic conditions, for both offshore and onshore locations. The effect of temperature and environmental ageing on the mechanical strength of the wind turbine blade structure also needs to be considered as factors that could affect the through life durability. These areas are recommended to be further studied in the future.

\section{Acknowledgements}

The authors would like to acknowledge the support of E.ON, as well as SSP-Technology A/S who have submitted the box girder. 


\section{References}

[1] L.G. Brazier, Late (1926), The Royal Aircraft Establishment. "The flexure of thin cylindrical shells and other 'thin' sections”. Reports and Memoranda no1081 (M.49).

[2] DNV/Risø publication, "Guidelines for Design of wind Turbines" $3^{\text {rd }}$ edition. Denmark. (2008).

[3] International Electrotechnical Commission. "IEC 61400-1: Wind turbine generator systems-Part 1: Safety Requirements". $2^{\text {nd }}$ edition, International standard 1400-1, (1999).

[4] J.K. Tadich, J. Wedel-Heinen, P. Petersen "New guidance for the development of wind turbine blades". Det Norske Veritas - Global Wind Energy conference, Copenhagen, Denmark. (2005).

[5] "Materials Challenges in Present and Future Wind Energy" B. Hayman, J. Wedel-Heinen, P. Brøndsted, MRS Bulletin, Vol. 33, April 2008.

[6] J. Korsgaard, T. K. Jacobsen "Integrated testing in reliable design of large wind turbine blades". LM Glasfiber A/S, Denmark.

[7] “Computational structural Analysis and Testing”. R. Krüger, S. Rinderknecht, C. Hänsel, M. König. University of Stuttgart Germany (1996)

[8] “Subcomponent Testing for Wind Turbine Blades” E. Stammes, A. González Canales,R. P. L Nijssen

[9] "Fatigue life prediction and strength degradation of wind turbine rotor blade composites” R. P. L. Nijssen. Technical University Delft.

[10] "Design, Structural testing, and cost effectiveness of sectional wind turbine blades” A. G. Dutton, C. Kildegaard, T. Dobbe, R. Bensoussan, C. Kensche, F. Hahn, D.R.V. van Delft, G. D. de Winkel. (November 2000)

[11] H. Stensgaard, J. D. Sørensen "Stochastic models for strength of wind turbine blades using tests”. H. Aalborg University, Denmark and Risø National Laboratory. EWEC (2008).

[12] DNV-OS-J102

[13] P. Berring, K. Branner, C. Berggreen, and H. W. Knudsen "Torsional Performance of wind Turbine Blades - Part I: Experimental Investigation”. (2007).

[14] P. Berring, K. Branner, C. Berggreen, and H. W. Knudsen "Torsional Performance of wind Turbine Blades - Part II: Numerical Validation”. (2007).

[15] T. von-Kármán Zeit. "Ueber die formänderung dünnwanger rohre, insbesondere federnder ausgleichrohre” Des vereines Deutscher Ingenieure. (1911)

[16] F. M. Jensen "Ultimate strength of a large wind turbine blade". PhD Thesis- RisøPhD-34(EN)-ISBN978-87-550-3634-5. Risø National Laboratory for Sustainable Energy, Technical University of Denmark. (May 2008)

[17] F. M. Jensen, B.G. Falzon, J. Ankersen, H. Stang "Structural testing and numerical simulation of a 34m. Composite wind turbine blade" Composite Structures 76 (2006).

[18] L. S. Cecchini, P. M. Weaver "The Brazier effect in multi-bay aerofoil sections". AIAA Jornal 43(10), 2005 pp 2252-2258

[19] L. S. Cecchini “The non-linear flexural response of thin-walled beams”. PhD-Thesis. University of Bristol - UK. (2006).

[20] C.L. Thomsen, Y. Eisenberg "Blade test SSP34\#2 Edgewise and Flapwise Final Static test”. Risø-I-2083(EN) 
[21] F. M. Jensen, P. M. Weaver, L. S. Cecchini, H. Stang, R. F. Nielsen, "The Brazier effect in Wind-Turbine Blades and its Influence on Design". (Submitted "Wind Energy, Dec. 2009)

[22] A. S. Puri, F. M. Jensen, J. P. Dear, A. Morris, I. Palmer, J. Ankersen, Investigating the impact of non-linear geometrical effects on wind turbine blade.Part 2: Experimental investigations of the interlaminar failure of load carryinglaminates (In progress)

[23] A. S. Puri, F. M. Jensen, J. P. Dear, P. Berring, R. Bitsche, K. Branner, M. McGugan, A. Morris, Investigating the impact of non-linear geometrical effects on wind turbine blade. Part 3: Experimental and numerical investigations of the failure of shear webs (In progress).

[24] A. S. “On Innovative Concepts of Future Wind Turbine Blade Design”, Find

M. Jensen,

Robert Bitsche, Tomasz Sieradzan, Agnieszka Roczek, Peter Berring, Kim Branner, NAFEMS NORDIC-Composite seminar, Esbjerg Feb. 2010.

[25] C. Berggreen, N. Tsouvalis, B. Hayman, and K. Branner "Buckling Strength of Thick Composite Panels in Wind Turbine Blades - Part I: Effect of Geometrical Imperfections”. 4th International conference on composites testing and model identification, 20-22, Dayton, Ohio, USA. (Submitted). (October 2008).

[26] K. Branner, P. Berring, and C. Berggreen "Buckling Strength of Thick Composite Panels in Wind Turbine Blades - Part II: Effect of Delamination”. 4th International Conference on Composites.

[27] K. Branner, F. M. Jensen, P. Berring, A. Puri, A. Morris, J. P. Dear "Effect of sandwich core properties on ultimate strength of a wind turbine blade". $8^{\text {th }}$ edition. International Conference on sandwich Structures. (April 2008)

[28] C. Jensen "Defects in FRP Panels and their influence on Compressive Strength". Master's Thesis. Technical University of Denmark and Risø National Laboratory. (February 2006)

[29] F. M. Jensen, K. Branner, P. H. Nielsen, P. Berring, T. S. Antvorskov, M. Nielsen, B. Lund, C. Jensen, J. H. Reffs, R. F. Nielsen, P. H. Jensen, M. McGugan, K. Borum, R. S. Hansen, C. Skamris, F. Sørensen, R. S. Nielsen, J. H. Laursen, M. Klein, A. Morris, A. Gwayne, H. Stang, J. Wedel-Heinen, J. P. Dear, A. Puri, A. Fergusson, "Full-scale Test of a SSP34m box girder 1 - Data Report”. Risø-R-RIS88(EN). (March 2008).

[30] F. M. Jensen, K. Branner, P. H. Nielsen, P. Berring, T. S. Antvorskov, M. Nielsen, J. H. Reffs, P. H., Jensen, M. McGugan, C. Skamris, F. Sørensen, R. S. Nielsen, J. H. Laursen, M. Klein, A. Morris, H. Stang, J. Wedel-Heinen, J. P. Dear, A. Puri, A. Fergusson "Full-scale Test of a SSP34m box girder 2 - Data Report”. Risø-R-1622(EN). (April 2008).

[31] F. M. Jensen, "Reinforced aerodynamic profile - cap reinforcement". PCT/DK2008/071195. (Dec. 2006).

[32] F. M. Jensen, "Reinforced blade for wind turbine - floor". PCT/DK2008/086805. (Jan. 2007).

[33] F. M. Jensen, P. H. Nielsen, "Reinforced blade for wind turbine - cross". PCT/DK2008/089765. (Jan. 2007).

[34] F. M. Jensen "Wind Turbine blade - U-Profile”. PCT/DK2008/092451. (Jan. 2007).

[35] F. M. Jensen "Reinforced blade for wind turbine - coupling of trailing edge panels". PCT/DK2009/155920. (June 2007).

[36] F. M. Jensen, P. H. Nielsen"Reinforced blade for wind turbine - soft floor". PCT/DK2010/000263. (June 2007). 
[37] F. M. Jensen, "Reinforced blade for wind turbine - angled girders". PCT/DK2009/155921. (June 2007).

[38] "Computational fracture Mechanics for Composites State of the Art and Challenges” R. Krueger USA (June 2006)

[39] K. Branner "Modelling Failure in Cross-Section of Wind Turbine Blade". Risø National Laboratory, NAFEMS-Seminar. Denmark (June 2006).

[40] ASTM International. "ASTM C364 Standard Test Method for edgewise compressive strength of flat sandwich constructions". (1989)

[41] "Buck Blade” Finite Element Buckling Analysis of Wind Turbine Blades. C. Lindenburg, T. Geiger, P. A. Joosse, B. Weisser. Netherland 


\section{Figures}

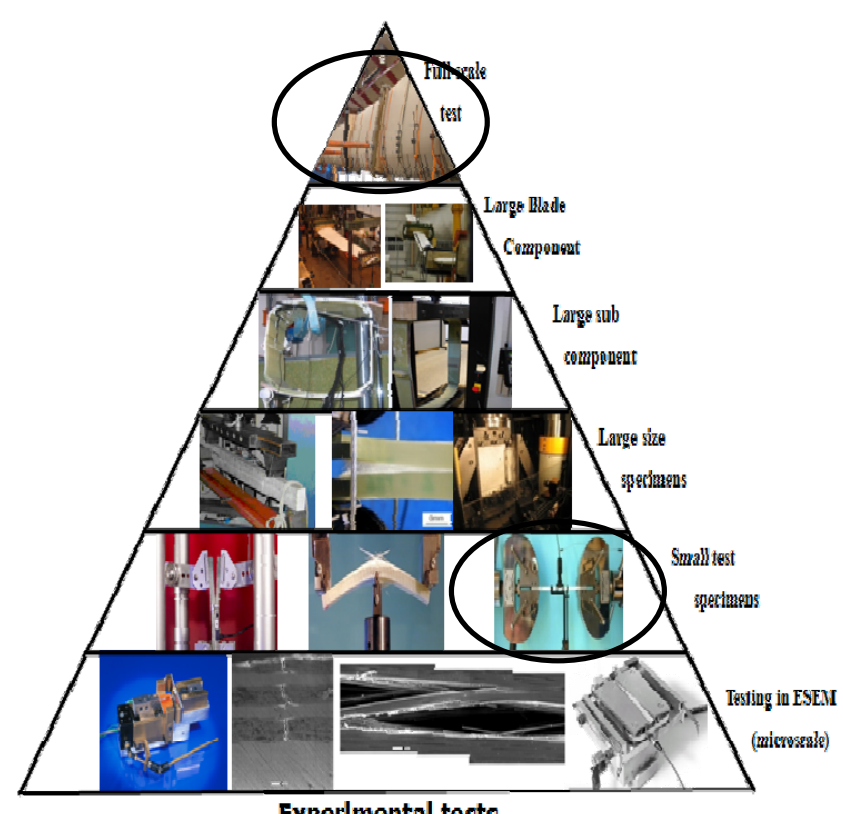

Experimental tests

Figure 1. Multi-scale approach for testing and analysis of wind turbine blades used at Risø DTU. The circles are tests which are required by the certifying agencies.
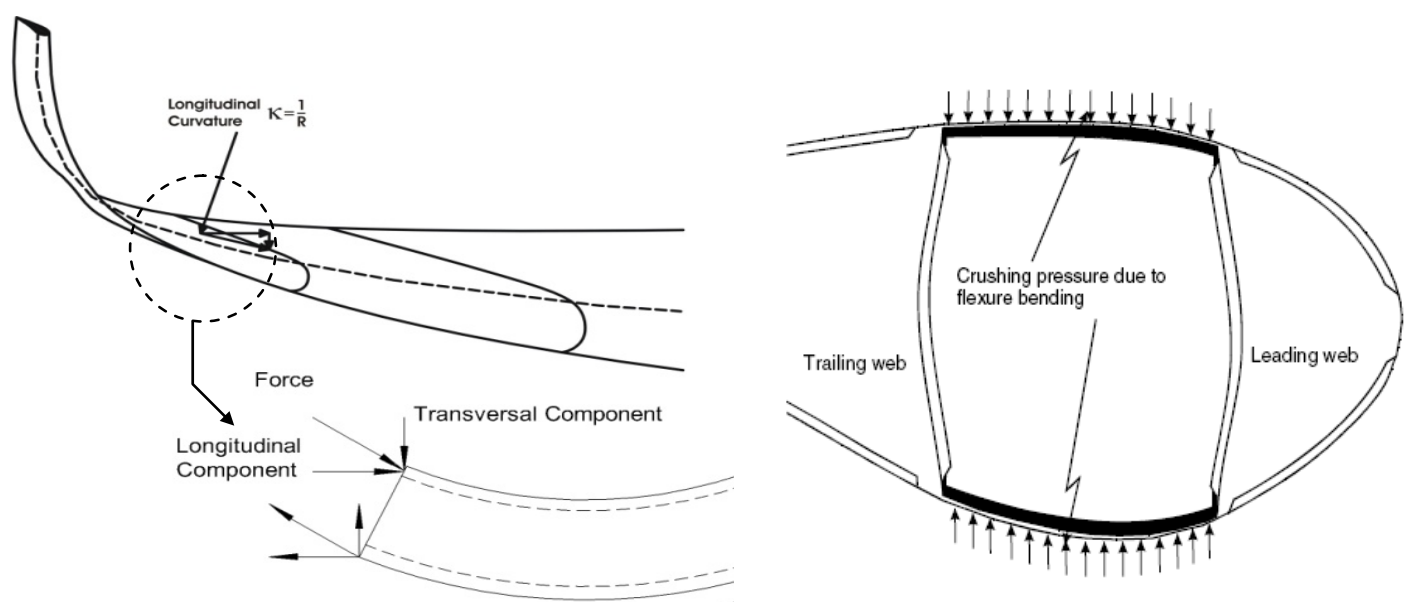

Figure 2. Brazier effect inducing crushing pressure on the box girder section, caused by the longitudinal bending, ref. [16],[18],[21].

Figure 3. Failure observed at the shear web of a box girder analysed in ref. [16],[21] a) Frozen frame picture showed skin debonding of the sandwich web towards leading edge b) Sketch which illustrates the failure and the strain gauges attached in that area. 


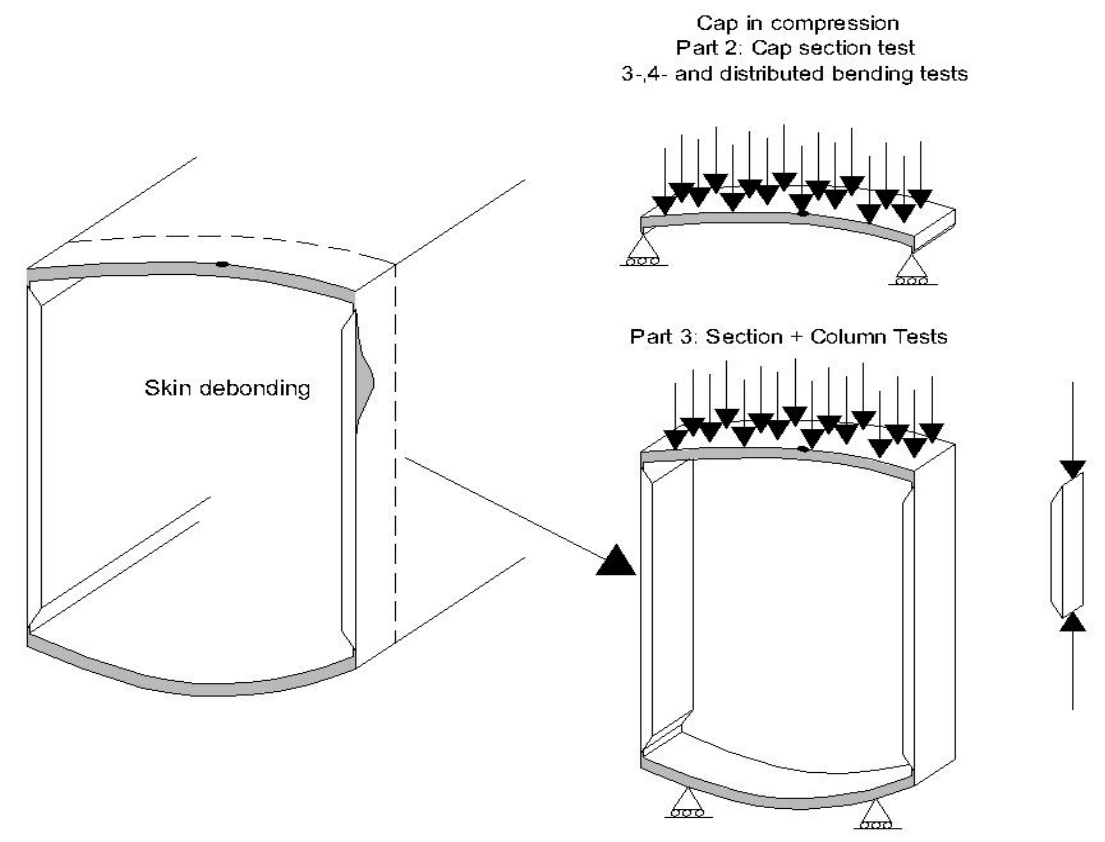

Figure 4. The three sub components which have been experimentally evaluated at Imperial College London (Department of Mechanical Engineering). Cap part experiment is analyzed in part 2 ref. [1] and section + column parts analyzed in part 3 ref. [2].

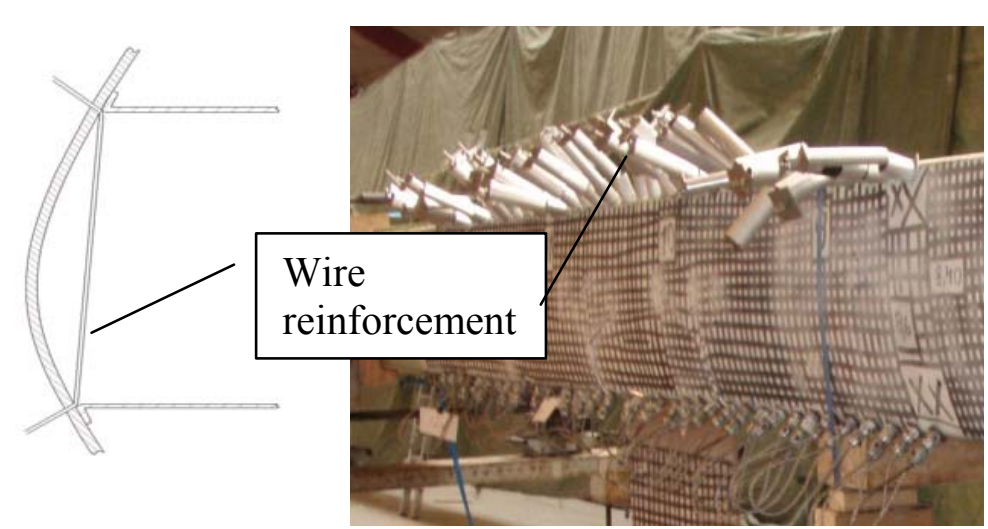

Fig. 5a

Fig. $5 b$

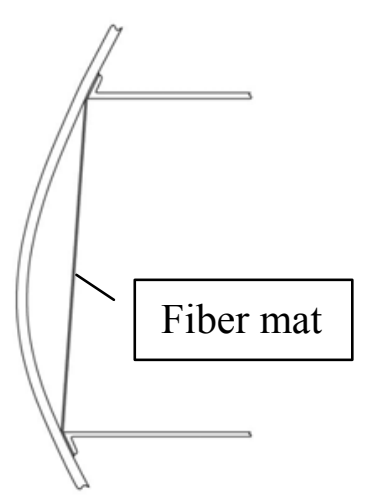

Fig. $5 \mathrm{c}$

Figure 5. Cap reinforcement. a) Sketch of uie wiाe ıenıforcement solution used in full-scale test of the load carrying box girder. b) The steel wire solution used in the full-scale test was specifically to validate the effect of the wire reinforcement. c) One example of a realistic reinforcement solution. 


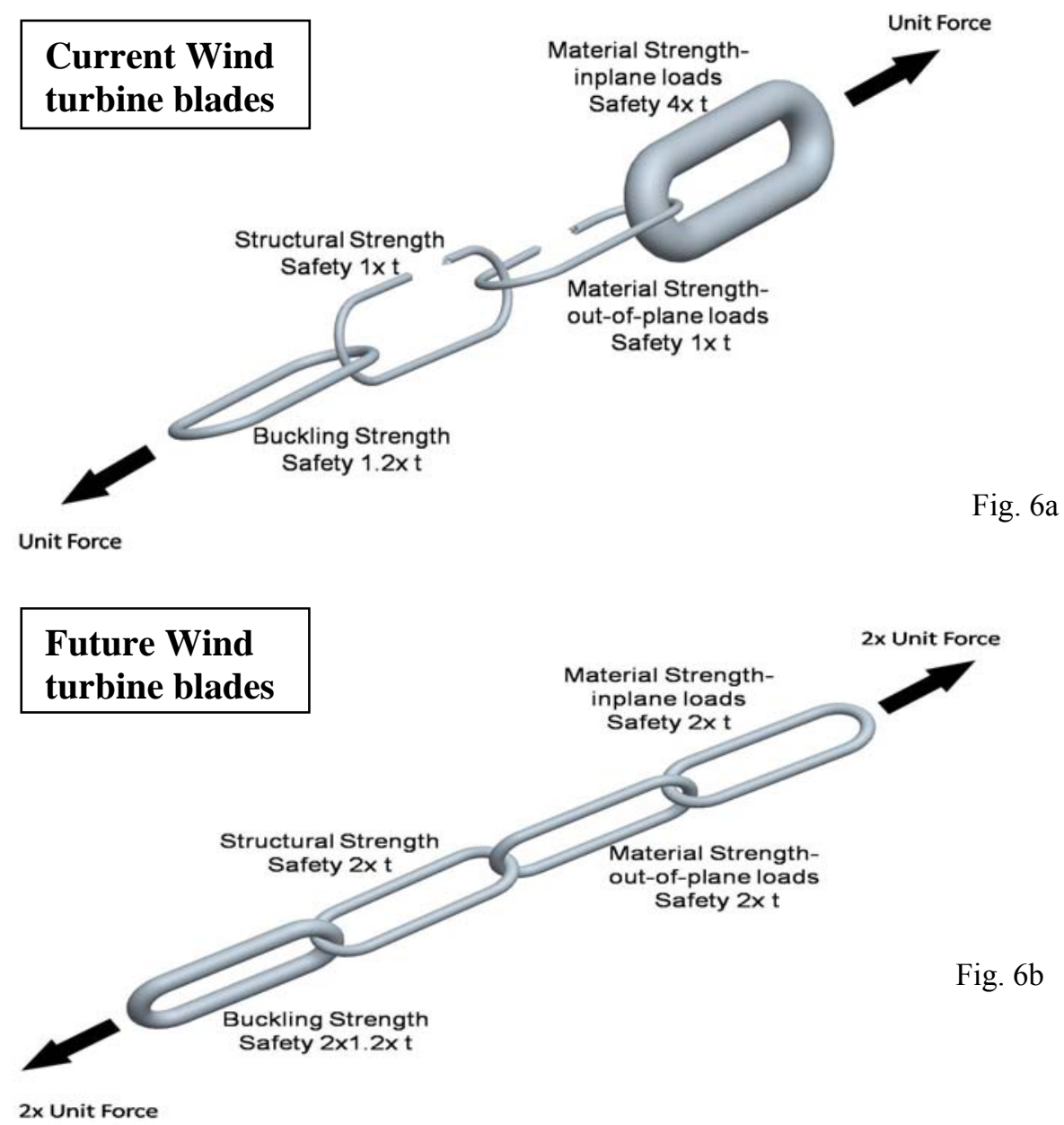

Figure 6. Illustration of the safety margins for current (a) and future (b) wind turbine blades. The parameter ' $t$ ' representing the thickness of the chain links illustrates the safety against ultimate failure. The figures are estimated based on recent research experience, [16]. The arrows represent the safety of the chain illustrated by unit forces. (b) The chain can carry two times the unit force while (a) only can carry one unit force.

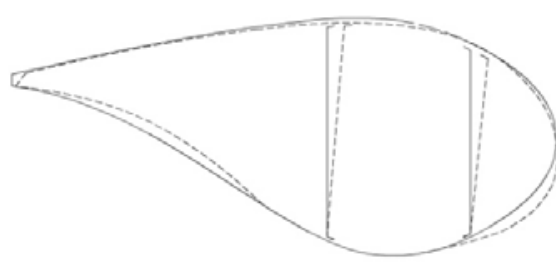

Fig. 7a

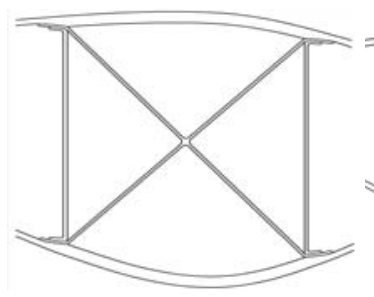

Fig. $7 b$

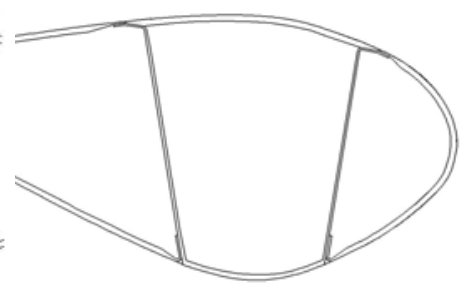

Fig. 7c

Figure 7. a) A sketch from ref. [16] of a distorted wind turbine profile b) Cross to avoid transverse shear distortion (dry fibremat solution shown - ref. [33]) c) Tilted shear webs do also prevent shear distortion - [37]. 


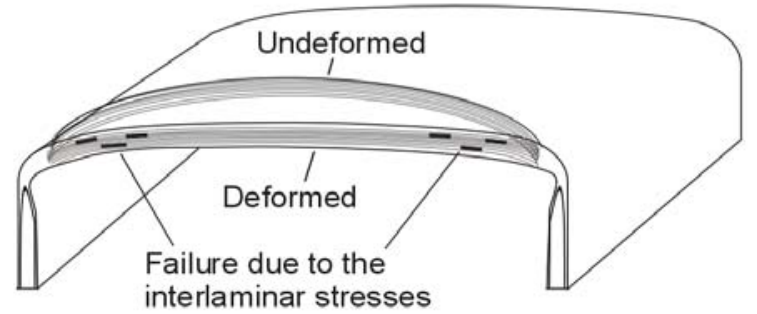

Fig. 8a

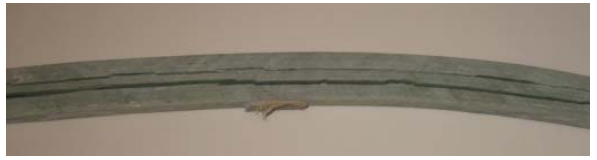

Fig. $8 \mathrm{~b}$

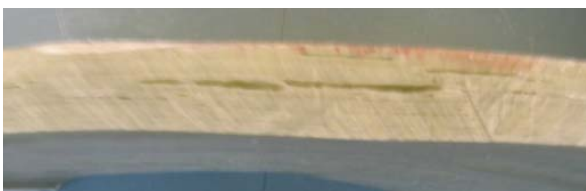

Fig. 8c

Figure 8. Interlaminar shear failure of the load-carrying cap. a) Sketch of cap deformation and failure between layers b) Photo of a cap with delamination c) Photo of a cap with a manufacturing defect.
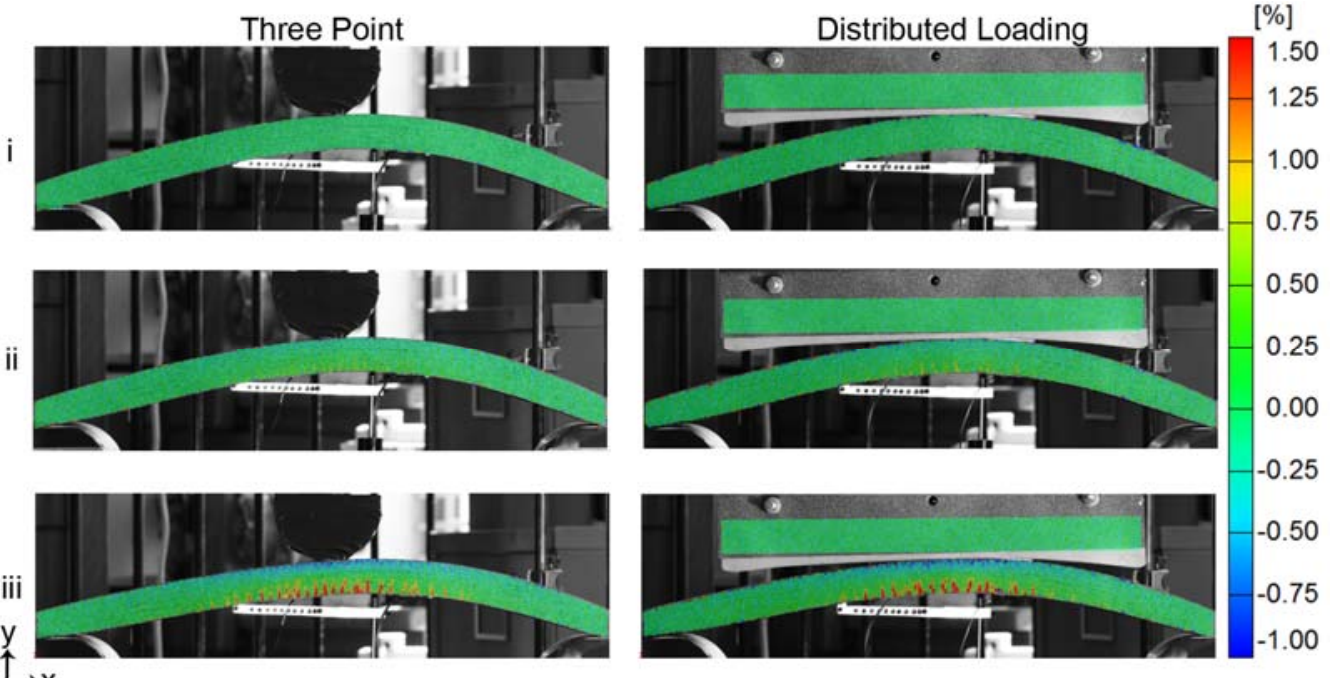

Fig. 9a

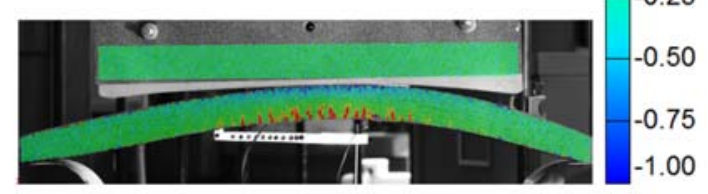

Fig. $9 \mathrm{~b}$

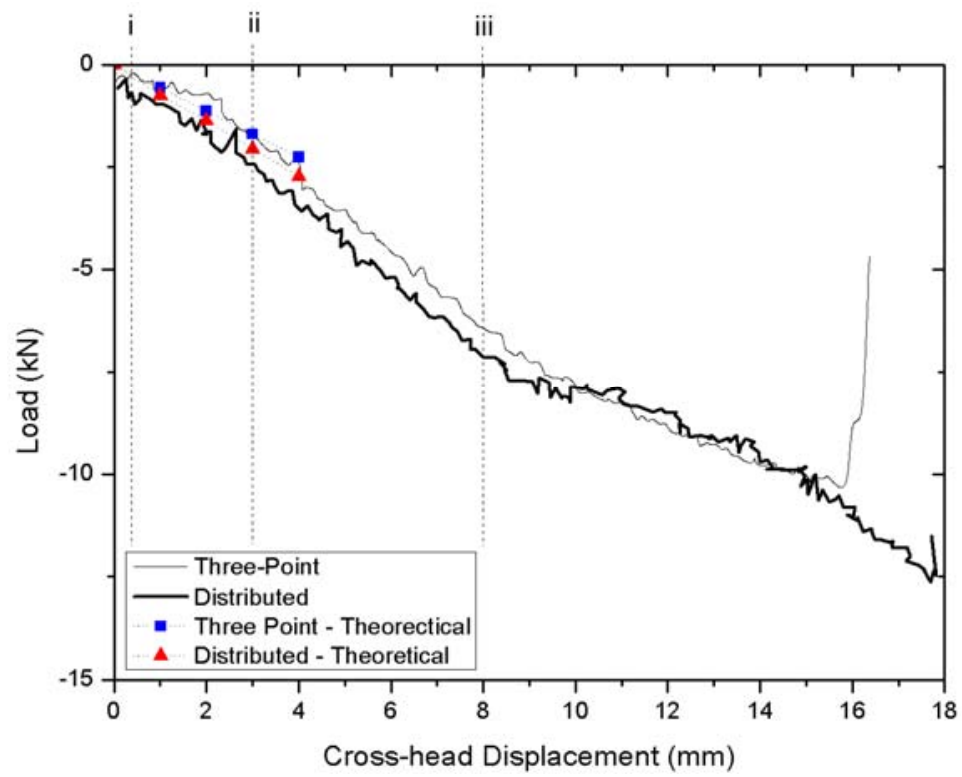

Fig. 9c

Figure 9. 3-point and distributed-load bending tests of two cap specimens. The bending tests are analyzed in paper 2, see ref. [22]. Subfigures a) and b) The overlaid contour plots shows the strains along axis $\left(\varepsilon_{\mathrm{x}}\right)$ of the test specimen (referring to the transverse strains in the box girder) caused by the bending loads c) The bending tests led to sustained delamination 
growth after $10 \mathrm{~mm}$ deflection in both bending tests. Theoretical curves based on bending theory for flat composite beams. Matrix cracking initiated between 8-10 mm cross-head displacement.

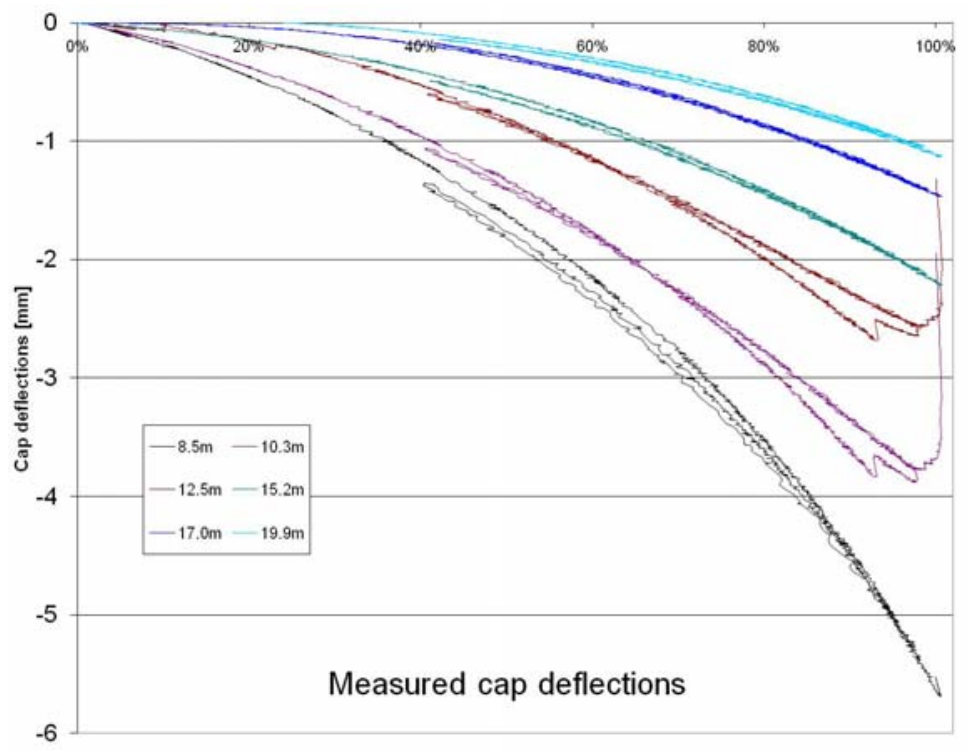

Figure 10. Cap deflections of the centreline measured in different sections. The results is from a fullscale test analyzed in ref. [16],[17],[29].

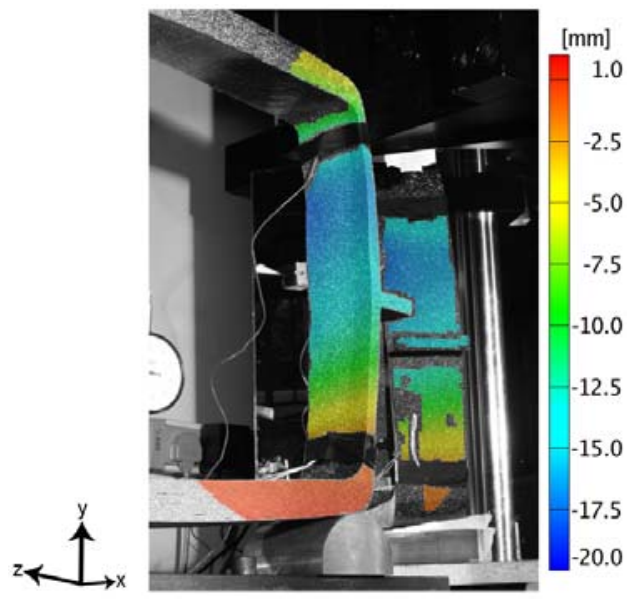

Fig. 11a

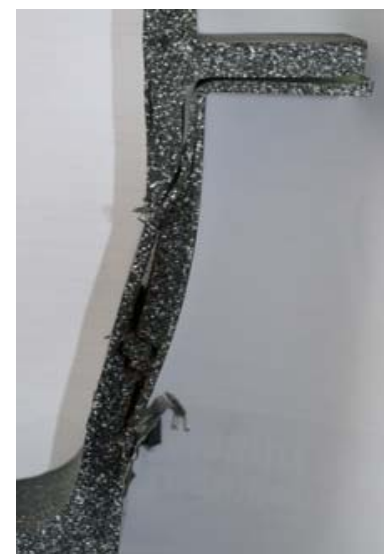

Fig. $11 \mathrm{~b}$

Figure 11. Box girder section test: a) z-displacement indicates non-uniform ovalisation of section (zdirection is perpendicular to flat face of section); b) shear fracture lead to loss of load bearing capacity.

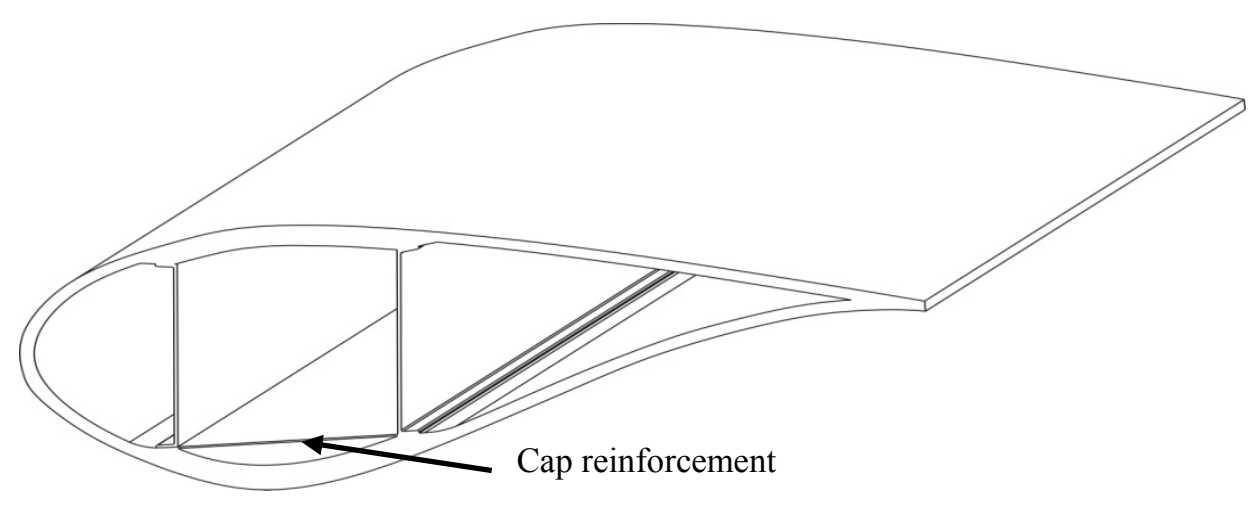


Figure 12. Sketch of the cap reinforcement which limits the curved cap from flattening out due to the corners being restrained from sideward deformations. Figure from patent application, see ref. [31].

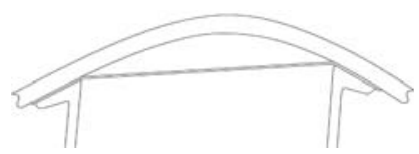

Fig. 13a

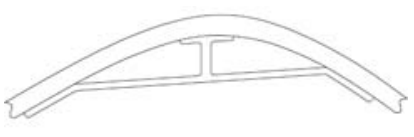

Fig. 13b

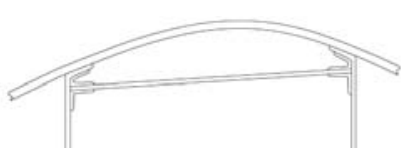

Fig. 13c

Figure 13. Different embodiments of the cap reinforcement from ref. [31] a) Dry fibre mat b) Pultruded profile c) Wire or pin solution

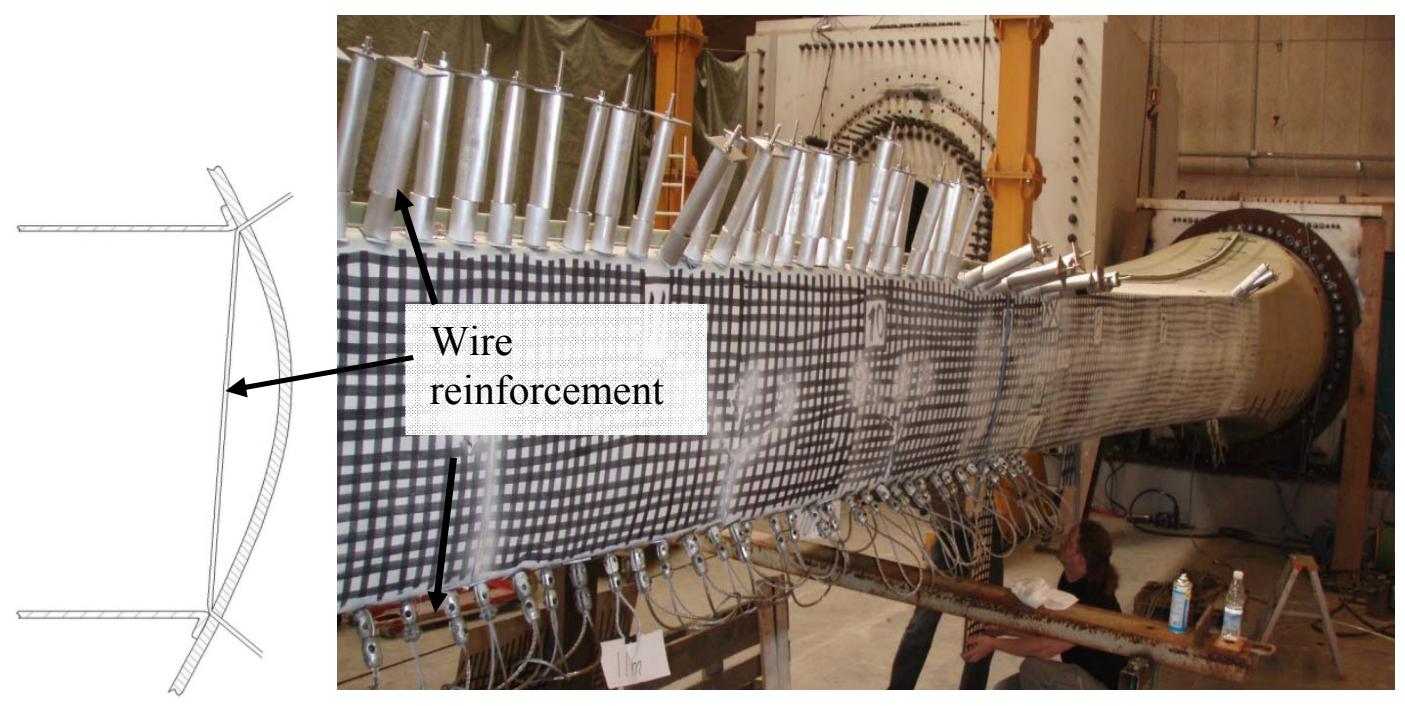

Fig. 14a

Fig. 14b

Figure 14. Full-scale test of a box girder with wire reinforcement as part of a 'proof of concept' for the cap reinforcement invention a) Sketch of the wire reinforcement solution used in the full-scale test b) Picture from the full-scale test.

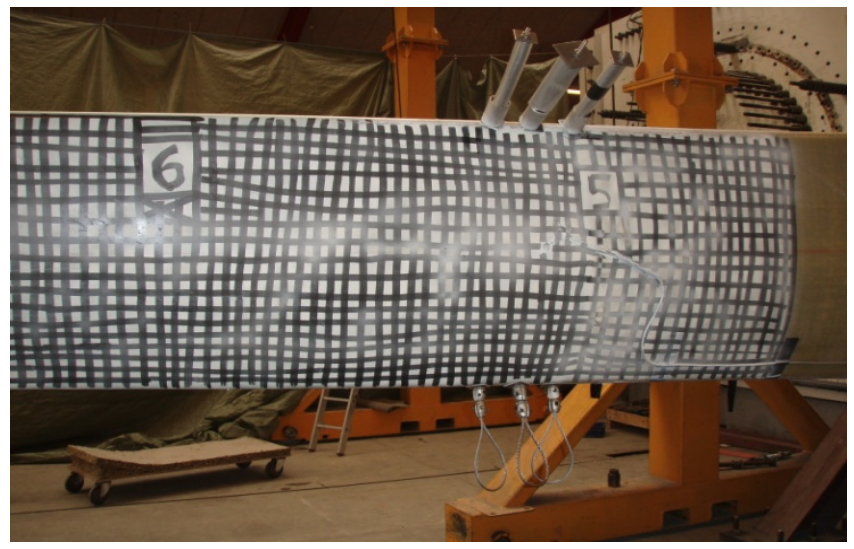

Fig. 15a

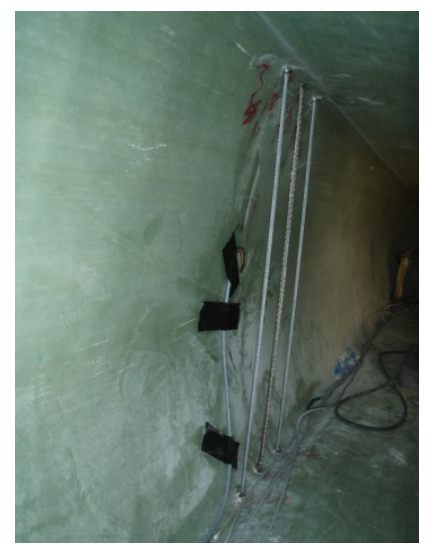

Fig. $15 b$

Figure 15. Wire reinforcement in $5 \mathrm{~m}$ region a) Photo outside the box girder which shows the wires in $5 \mathrm{~m}$ b) Photo inside the box girder. 


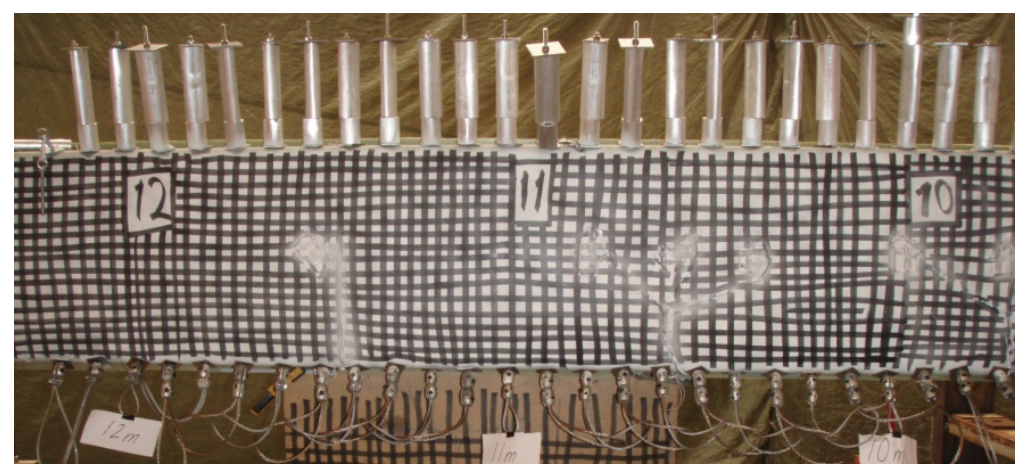

Fig. 16a

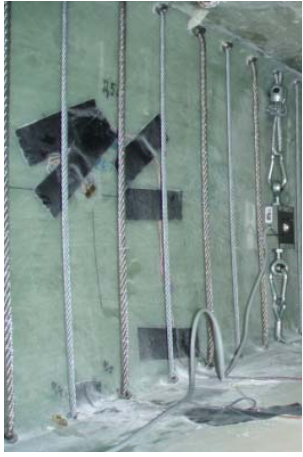

Fig. 16b

Figure 16. Wire reinforcement in $8.5-12 \mathrm{~m}$ region (only $10-12 \mathrm{~m}$ shown a) Photo outside the box girder which shows the wires in $10-12 \mathrm{~m}$ b) Photo inside the box girder.

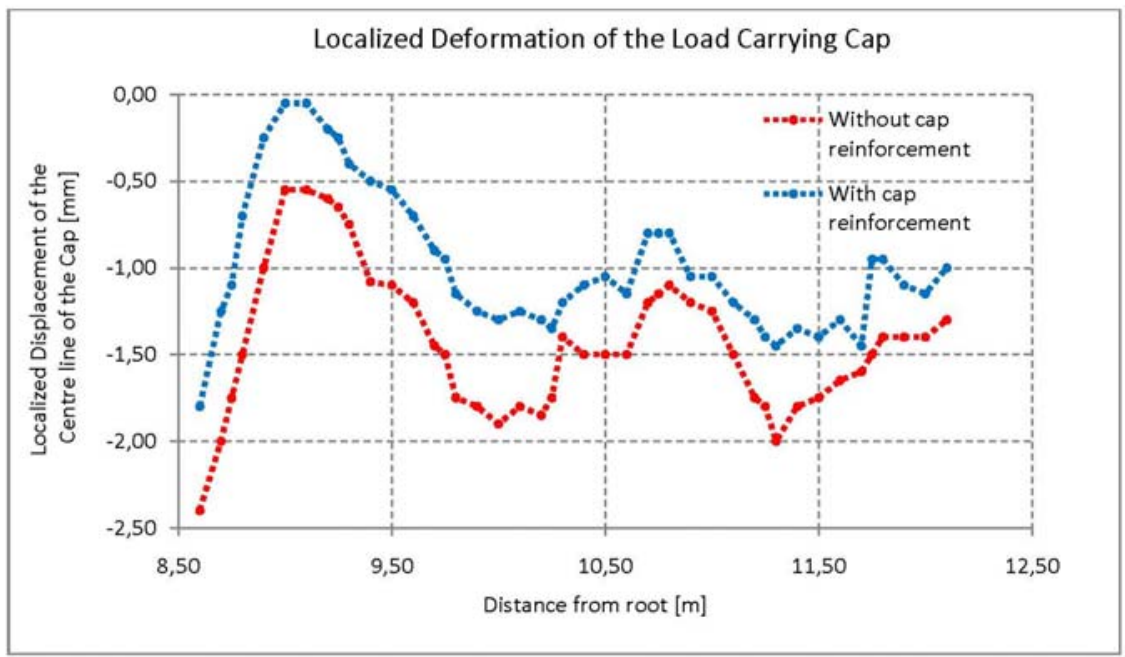

Figure 17. Cap deformations measured using ARAMIS DIC system. Two curves show the cap deformations of the centreline. Red line is from test without wires and blue line is from test with wires. Details can be found in ref. [29].

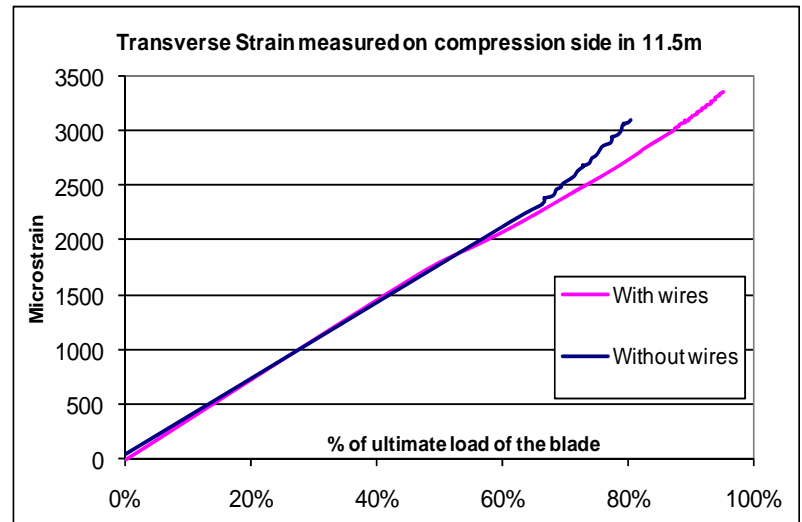

Fig. 18a

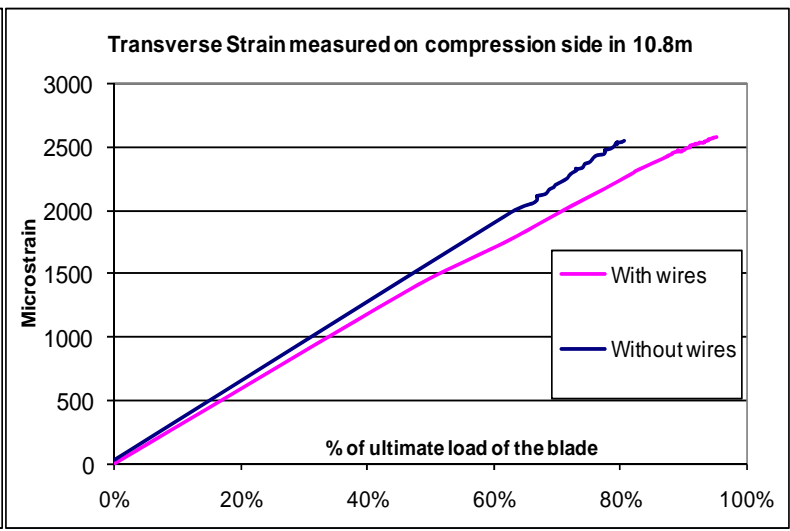

Fig. $18 b$

Figure 18. Transverse strain measurements with and without cap reinforcement. a) Measurements for section $11.5 \mathrm{~m}$ shows that buckling capacity increases when the cap reinforcement is included b) Measurements for section $10.8 \mathrm{~m}$ show reduced strain when the cap reinforcement is included. 